\title{
Implementasi Six Sigma untuk Perbaikan Produk Nickel Pig Iron
}

\author{
Mohamad Jihan Shofa ${ }^{1}$, dan Hadi Gunawan ${ }^{2}$ \\ Program Studi Teknik Industri, Fakultas Teknik, Universitas Serang Raya \\ m.j.shofa@gmail.com; gunawan.hadi03@yahoo.co.id
}

\begin{abstract}
Abstrak -- PT. INF merupakan sebuah perusahaan yang bergerak pada bidang pertambangan baja dengan produk berupa nickel pig iron. Nickel pig iron digunakan bahan baku pabrik stainless steel, nickel dan gulungan pabrik baja. Jumlah produk cacat untuk nickel pig iron dalam beberapa bulan mengalami trend kenaikan. Penelitian ini akan menganalisis penyebab terjadinya kenaikan cacat produk dengan menggunakan metodologi Six Sigma. Selanjutnya, usulan perbaikan dilakukan dengan menggunakan pendekatan failure mode and effect analysis (FMEA). Hasil penelitian didapatkan bahwa problem yang menjadi apareto dalam proses adalah pertama nilai Silika (Si) tinggi dan kedua fospor $(P)$ tinggi, level sigma yang didapatkan dari proses pembuatan pig iron rata-rata tahunan sebesar 1,6 sigma, perbaikan proses yang perlu dilakukan adalah pengawasan terhadap penjadwalan order burnlime powder, pengecekan material baru dengan uji coba formula terhadap material baru, dan pembuatan jadwal perbaikan serta fokus terhadap perubahan tekanan yang rertera pada layar monitor
\end{abstract}

Kata kunci: FMEA; Nickel Pig Iron;dan Six Sigma

\begin{abstract}
PT. INF is a steel mining company. It produce such as nickel pig iron. Nickel pig iron used raw materials stainless steel factory, nickel and steel mill rolls. The number of defective products for nickel pig iron in a few months getting on upward trend. This research will analyze the cause of the increasing defect product by using Six Sigma methode. Furthermore, the proposed improvement is done by using the failure mode and effect analysis (FMEA) approach. The results shows the main problems are the higher value of Silica $(S i)$ and phospor $(P)$, the sigma level is obtained from the annual pig iron making process in 1.6 sigma, process improvement need to be done are monitoring and scheduling of burnlime powder orders, checking new materials by testing the formula against new materials, and making a repair schedule as well as focusing on changes in pressure on the monitor screen
\end{abstract}

Keywords: FMEA; Nickel Pig Iron; and Six Sigma

\section{PENDAHULUAN}

Beberapa dekade terakhir, peranan industri manufaktur dalam perekonomian Indonesia mengalami peningkatan substansial. Persaingan di pasar global mengharuskan produk memiliki kualitas baik. Kualitas merupakan suatu produk dan jasa yang melalui tahapan proses dengan memperhitungkan nilai tanpa adanya kekurangan sedikitpun nilai tersebut dan menghasilkan produk dan jasa sesuai harapan pelanggan (Prijati, 2016). Pemenuhan produk yang berkualitas mempunyai tujuan untuk memenuhi kepuasan pelanggan dan keberlangsungan jangka panjang produk tersebut. Dengan demikian, pengendalian kualitas merupakan mutlak dilakukan dalam rangka pemenuhan kepuasan.

Untuk melakukan pengendalian kualitas, dapat dilakukan pengendalian kualitas terpadu dengan cara menjalankan usaha untuk memaksimumkan daya saing melalui perbaikan terus menerus (continous improvement) atas produk atau bahan baku (Gasperz, 2008). Penerapan pengendalian kualitas bertujuan untuk meningkatkan efektifitas perusahaan dalam mencegah terjadinya cacat produksi sehingga mampu meminimalkan pemborosan yang diakibatkan dari sisi material, tenaga kerja maupn biaya lain yang harus dikeluarkan.

PT. INF merupakan sebuah perusahaan yang bergerak pada bidang pertambangan baja dengan produk berupa nickel pig iron. Nickel pig iron digunakan sebagai bahan baku pabrik stainless steel, nickel, dan gulungan pabrik baja. Pada proses produksi jumlah produk cacat nickel pig iron dalam beberapa bulan mengalami trend kenaikan sampai $4.542 .810 \mathrm{~kg}$ unit (gambar 1) yang disebabkan terjadinya trouble shooting yang berdampak pada tingginya kandungan Silik (Si) \& fosfor (P). Trend peningkatan cacat produk ini menjadi bahan evaluasi dan perbaikan proses sehingga produk 
yang dihasilkan ke depan menjadi lebih baik lagi.

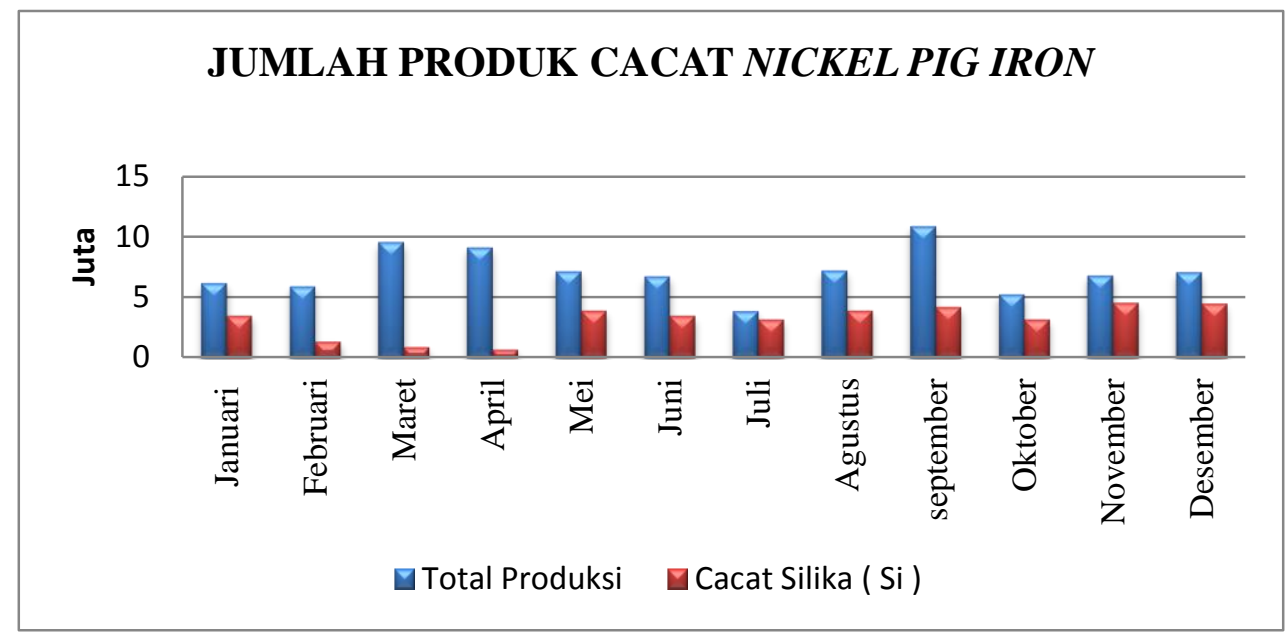

Gambar 1. Jumlah Produk Cacat Nickel Pig Iron Januari-Desember

Salah satu metode perbaikan yang dapat digunakan adalah Six Sigma. Six Sigma adalah metode yang dapat digunakan untuk meningkatkan efektivitas dan efesiensi secara bersamaan (Eckes, 2003). Berbagai penelitian implementasi Six Sigma sudah dilakukan di berbagai bidang dan telah memberikan hasil yang perbaikan signifikan seperti manufaktur (Indrawati \& Ridwansyah, 2015), pendidikan (Patil, Kamlapur, \& Dhore, 2006), kontruksi (Han, Chae, Im, \& Ryu, 2008), perbankan (Putri, Gunawan, \& Sutanto, 2017), dan kesehatan (J. Liberatore, 2013).

Dari beberapa penelitian tersebut, peneliti menggunakan pendekatan Six Sigma untuk perbaikan kualitas pada proses produksi blast furnace yang digunakan sebagai treatment dalam menghasilkan kualitas pig iron yang sesuai standard.

\section{METODOLOGI PENELITIAN}

Menurut Salomon, Ahmad, \& Limanjaya (2017) Six Sigma adalah merupakan suatu program peningkatan kualitas untuk memperbaiki kegiatan proses produksi yang berfokus pada pengurangan variansi proses menuju 3,4 kegagalan per sejuta produksi. Jadi Six Sigma merupakan teknik pengendalian dan peningkatan kualitas dalam rangka meningkatkan kepuasan pelanggan.

Pada prinsipnya pelanggan akan puas apabila menerima sesuatu sesuai dengan yang diharapkan. Dengan penggunaan Six Sigma pada peningkatan kualitas produk, maka Perusahaan bisa mengharapkan 3,4 kegagalan per sejuta produk.
Six Sigma adalah metodologi perbaikan yang mengedepankan pada perbaikan berkelanjutan (continuous improvement). Ada 5 tahapan Six Sigma yang disebut dengan DMAIC (Define, Measure, Analyze, Improve dan contro). pada penelitian ini dilakukan tahapan sampai Improve.

\section{Define}

Define merupakan tahapan penetapan sasaran peningkatan kualitas Six Sigma. Langkah ini mendefinisikan rencana tindakan yang harus dilakukan untuk melaksanakan peningkatan dari setiap tahapan proses. Pada tahapan ini dilakukan dengan langkah penentuan pernyataan proyek penelitian dan pembuatan Diagram SIPOC (Suppliers, input, processes, output dan costumers)

\section{Measure}

Measure merupakan langkah operasional yang kedua dalam program peningkatan kualitas Six Sigma. Dalam measure dilakukan penentuan CTQ (Critical to Quality) dan penilaian nilai sigma.

\section{Analyze}

Pada tahapan analyze dilakukan identifikasi masalah dan berusaha menemukan sumber penyebab masalah dengan menggunakan diagram sebab akibat. Diagram ini membentuk cara membuat produk lebih baik dan mencapai hasil yang lebih baik.

Failure Made and Effect Analysis (FMEA) merupakan penaksiran elemen per elemen secara otomatis untuk melihat akibat dari 
kegagalan komponen. FMEA adalah metode yang digunakan untuk menekan kerugian yang timbul karena kegagalan produk sewaktu digunakan oleh pengguna. FMEA mampu mengidentifikasi potensi kegagalan yang ada dalam proses, kemudian dilakukan pembobotan untuk mendapatkan prioritas terhadap potensi kegagalan yang perlu mendapatkan prioritas perbaikan (Wagner, Taroepratjeka, \& Mustofa, 2015). Dengan penggunaan FMEA dapat diketahui dengan mengidentifikasi kegagalan yang mungkin terjadi, member skala prioritas dari setiap jenis kegagalan, dan melakukan tindakan perbaikan

\section{Improve}

Improve merupakan tahapan setelah dilakukan analisa penyebab masalah. Pada tahap ini diberikan beberapa usulan perbaikan untuk meminimalkan penyebab masalah yang ada.

\section{PENGOLAHAN DATA DAN PEMBAHASAN}

Langkah-langkah pengolahan data menggunakan tahapan Six Sigma sampai dengan tahapan improve.

\section{Tahapan Pendefinisian (Define)}

Tahapan define pada tahap awal ini akan dilakukan pernyataan proyek penelitian. Penelitian ini fokus pada penurunan kualitas pada produksi pig iron yaitu seperti nilai kandungan persentase Silika (Si) \& fosfor (P) tinggi

Pembuatan diagram SIPOC bertujuan mengetahui dan mengidentifikasi proses produksi pig iron secara umum. Salah satu pemetaan yang efektif adalah diagram SIPOC. Diagram ini menunjukkan gambaran umum perusahaan yang terdiri dari Suppliers, input, processes, output dan costumers.

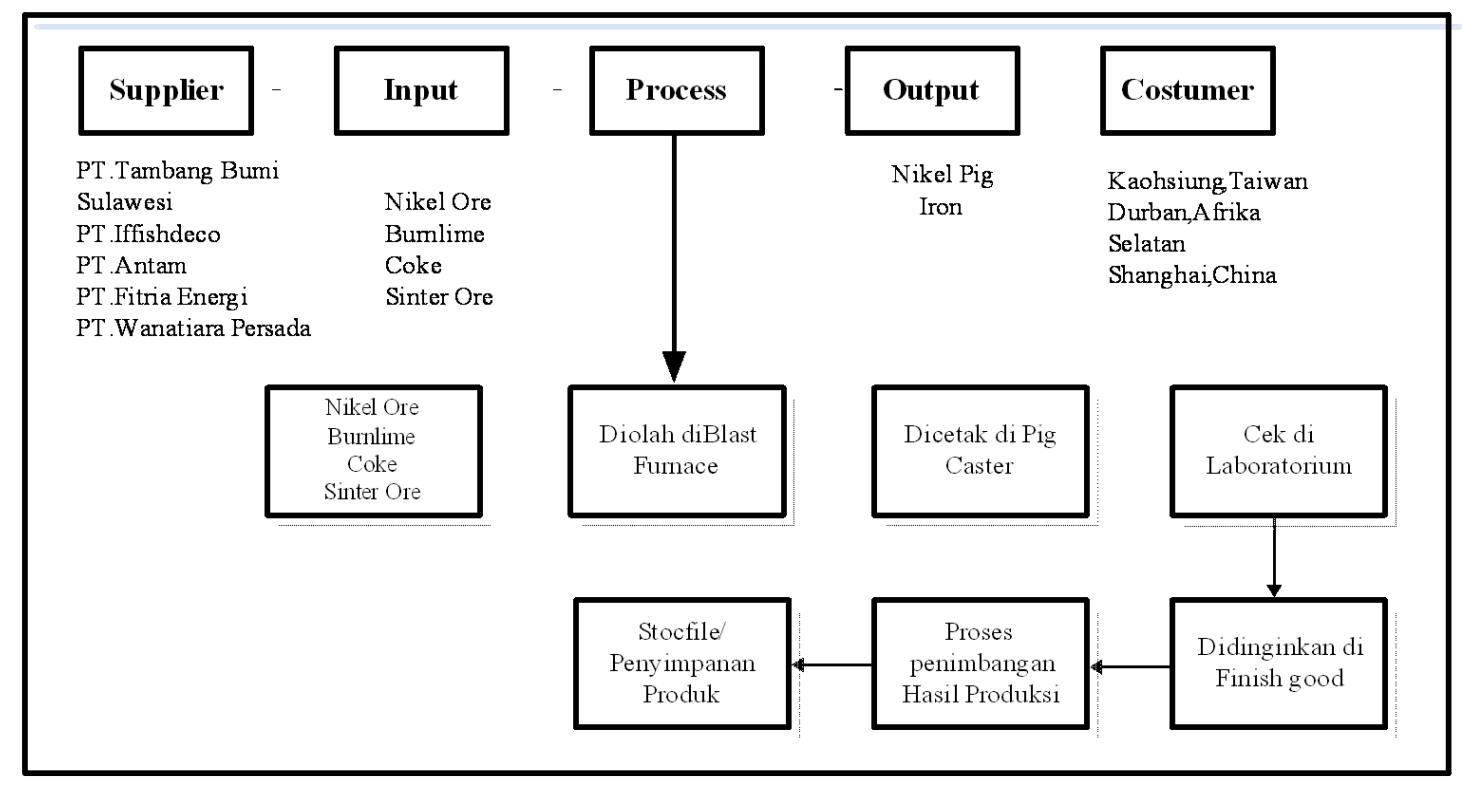

Gambar 2. Diagram SIPOC Proses Produksi Pig Iron

\section{Tahapan Pengukuran (Measure)}

Dilakukan perhitungan base line terhadap proses mesin blast furnace untuk mengetahui level kualitas dari proses mesin tersebut. Setelah dilakukan analisis didapatkan bahwa level sigma untuk proses tersebut pada range
0,6-2,9 sigma dengan rata-rata tahunan sebesar 1,6 sigma (Tabel 1), dengan demikian mengacu pada prinsip Six Sigma maka proses tersebut harus mendapatkan perhatian untuk dilakukan perbaikan. 
Tabel 1. Analisis base line untuk proses blast furnace

\begin{tabular}{|c|c|c|c|c|c|}
\hline Bulan & $\begin{array}{c}\text { Jumlah } \\
\text { Produksi }\end{array}$ & $\begin{array}{c}\text { Jumlah } \\
\text { reject }\end{array}$ & CTQ & DPMO & $\begin{array}{c}\text { Level } \\
\text { Sigma }\end{array}$ \\
\hline Januari & 6.185 .680 & 3.497 .370 & 2 & $565.397,8$ & 1.3 \\
\hline Februari & 5.897 .820 & 1.342 .600 & 2 & $227.643,4$ & 2.2 \\
\hline Maret & 9.566 .720 & 888.340 & 2 & $92.857,3$ & 2.8 \\
\hline April & 9.140 .260 & 698.780 & 2 & 76450,8 & 2.9 \\
\hline Mei & 7.165 .020 & 3.904 .680 & 2 & $544.964,3$ & 1.4 \\
\hline Juni & 6.750 .800 & 3.480 .600 & 2 & $666.833,5$ & 1.1 \\
\hline Agustus & 7.223 .140 & 3.919 .100 & 2 & $820.460,6$ & 0.6 \\
\hline September & 10.878 .160 & 4.213 .880 & 2 & $542.575,7$ & 1.4 \\
\hline Oktober & 5.256 .220 & 3.167 .720 & 2 & $387.370,7$ & 1.8 \\
\hline November & 6.812 .510 & 4.542 .810 & 2 & $602.661,2$ & 1.2 \\
\hline Desember & 7.074 .820 & 4.480 .620 & 2 & $633.319,3$ & 1.2 \\
\hline Jumlah & $\mathbf{8 5 . 8 1 5 . 6 5 0}$ & $\mathbf{3 7 . 3 0 7 . 1 7 0}$ & & $\mathbf{5 6 7 . 6 1 1 7 , 9}$ & $\mathbf{1 9 . 4}$ \\
\hline Rata-rata & $\mathbf{7 . 1 5 1 . 3 0 3 , 1 7}$ & $\mathbf{3 . 1 0 8 . 9 3 0 , 8 3 3}$ & & $\mathbf{4 7 3 . 0 0 9 , 8 3}$ & $\mathbf{1 . 6 2}$ \\
\hline
\end{tabular}

\section{Tahapan Analisis (Analyze)}

Analisis penyebab terjadinya kadar silika tinggi dilakukan dengan menggunakan fishbone diagram sebagai mana pada gambar 3 yang disebabkan dari faktor manusia yang kurang memahami bahasa asing, faktor bahan baku yang sesuai spesifikasi tinggal sedikit, dan faktor mesin, yaitu sering terjadi trouble shooting yang disebabkan tidak adanya penjadwalan perbaikan pada mesin dan pasokan sinter ore ke area blast furnace berkurang dikarenakan conveyor yang membawa material ke blast furnace rusak karena tidak tahan panas terhadap sinter ore.

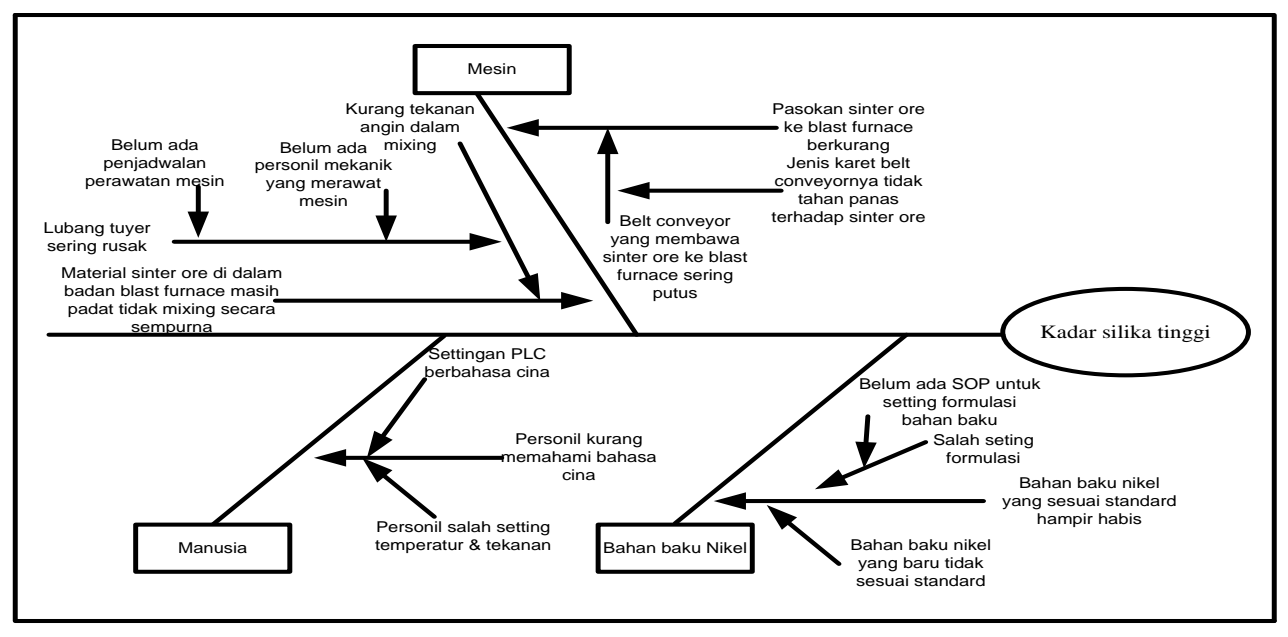

Gambar 3. Fishbone Diagram untuk Kadar Silika Tinggi

Analisis FMEA (failure mode and effect analysis) dilakukan untuk melihat potensi dan kegagalan yang muncul dari proses pembuatan dan dilakukan perbaikan terhadap proses berdasarkan pada nilai risk priority number (RPN) terbesar (tabel2) 
Tabel 2. FMEA untuk Proses Nickel Pig Iron

\begin{tabular}{|c|c|c|c|c|c|c|c|c|}
\hline Proses & $\begin{array}{c}\text { Mode } \\
\text { Kegagalan }\end{array}$ & $\begin{array}{l}\text { Potensi efek } \\
\text { kegagalan }\end{array}$ & $\mathrm{S}$ & $\begin{array}{c}\text { Penyebab potensi } \\
\text { kegagalan }\end{array}$ & $\mathrm{O}$ & Tindakan Antisipasi & $\mathrm{D}$ & RPN \\
\hline $\begin{array}{l}\text { Proportio } \\
\quad \text { ning }\end{array}$ & $\begin{array}{l}\text { Bahan baku } \\
\text { burnlime/ki } \\
\text { ln tidak } \\
\text { mencukupi }\end{array}$ & $\begin{array}{c}\text { Hasil } \\
\text { pencampuran } \\
\text { tidak maksimal }\end{array}$ & 1 & $\begin{array}{l}\text { Keterlambatan order } \\
\text { burnlime powder dari } \\
\text { suppliers }\end{array}$ & 5 & $\begin{array}{c}\text { Pengawasan terhadap } \\
\text { penjadwalan order burnlime } \\
\text { powder }\end{array}$ & 3 & 15 \\
\hline Sinter ore & $\begin{array}{l}\text { Bahan baku } \\
\text { nikel ore } \\
\text { baru }\end{array}$ & $\begin{array}{l}\text { Sinter ore yang } \\
\text { defect tercampur } \\
\text { dengan sinter ore } \\
\text { yang di targetkan }\end{array}$ & 5 & $\begin{array}{c}\text { Uji coba formula salah } \\
\text { atau gagal }\end{array}$ & 7 & $\begin{array}{l}\text { Sebelum material baru } \\
\text { datang harus ada uji coba } \\
\text { formula terhadap material } \\
\text { baru yang akan datang. }\end{array}$ & 6 & 210 \\
\hline $\begin{array}{l}\text { Blast } \\
\text { Furnace }\end{array}$ & $\begin{array}{c}\text { Tuyer } \\
\text { sering rusak }\end{array}$ & $\begin{array}{l}\text { Hasil produksi } \\
\text { blast furnace } \\
\text { banyak yang } \\
\text { defect }\end{array}$ & 6 & $\begin{array}{c}\text { Keterlambatan } \\
\text { komunikasi antara divisi } \\
\text { blower \& blast furnace } \\
\text {;Tools : tuyer rusak } \\
\text { karena tersumbat material }\end{array}$ & 4 & $\begin{array}{c}\text { Dibuatkan jadwal perbaikan } \\
\text { dan fokus terhadap } \\
\text { perubahan tekanan yang } \\
\text { rertera pada layar monitor }\end{array}$ & 7 & 168 \\
\hline
\end{tabular}

Kaitan antara Fishbone dan FMEA yaitu pada proses sinter ore dimana komposisi perbandingan untuk formula atau setting tidak sesuai, dikarenakan material nikel ore yang di gunakan adalah material baru sehingga operator harus memahami terlebih dahulu karakteristik atau sifat dari bahan baku baru tersebut.

\section{Tahapan Perbaikan (Improve)}

Berdasarkan pada analisis di atas ada beberapa tindakan perbaikan yang diusulkan yaitu:

a. Pengawasan terhadap penjadwalan order burnlime powder

b. Sebelum material baru datang harus ada uji coba formula terhadap material baru yang akan datang.

c. Dibuatkan jadwal perbaikan dan fokus terhadap perubahan tekanan yang rertera pada layar monitor

\section{KESIMPULAN}

Berdasarkan pada penelitian ini dapat disimpulkan problem yang menjadi masalah dalam penelitian ini adalah pertama nilai Silika (Si) tinggi dan kedua fospor (P) tinggi. Level sigma yang didapatkan dari proses pembuatan pig iron rata-rata tahunan sebesar 1,6 sigma. Perbaikan proses yang perlu dilakukan adalah pengawasan terhadap penjadwalan order burnlime powder, pengecekan material baru dengan uji coba formula terhadap material baru, dan pembuatan jadwal perbaikan serta fokus terhadap perubahan tekanan yang rertera pada layar monitor

\section{DAFTAR PUSTAKA}

Eckes, G. (2003). Six Sigma for everyone. New Jersey: John Wiley \& Sons, Inc.

Han, S. H., Chae, M. J., Im, K. S., \& Ryu, H. D. (2008). Six sigma-based approach to improve performance in construction operations. Journal of Management in Engineering, 24(1), 21-31.

Indrawati, S., \& Ridwansyah, M. (2015). Manufacturing Continuous Improvement Using Lean Six Sigma: An Iron Ores Industry Case Application. In Procedia Manufacturing (Vol. 4, pp. 528-534). Elsevier.

J. Liberatore, M. (2013). Six Sigma in healthcare delivery. International Journal of Health Care Quality Assurance, 26(7), 601-626.

Patil, V. H., Kamlapur, S. M., \& Dhore, M. L. (2006). Six Sigma in education: to achieve overall excellence in the field of education. In Information Technology: New Generations, 2006. ITNG 2006. Third International Conference on (pp. 2-5). IEEE.

Prijati, O. Y. (2016). Pengaruh Kualitas Produk, Harga, Dan Citra Merek Terhadap Keputusan Pembelian Honda Vario, 5(7), $1-20$.

Putri, N. T., Gunawan, A., \& Sutanto, A. (2017). The Consequences of Lean Six Sigma on Banking Improvement: A Study at a FrontLine Unit of a Bank Company in Indonesia. 
In International Conference on Applied Human Factors and Ergonomics (pp. 227237). Springer.

Salomon, L. L., Ahmad, A., \& Limanjaya, N. D. (2017). Strategi Peningkatan Mutu Part Bening Menggunakan Pendekatan Metode Six Sigma (Studi Kasus Departement Injection di PT. KG). Jurnal Ilmiah Teknik Industri, 3(3).

Wagner, R. M., Taroepratjeka, H., \& Mustofa, F. H. (2015). Usulan Peningkatan Kualitas Produk E-House Menggunakan Metode FailureMode and Error Analysisi (FMEA) di PT X. Reka Integra, 3(2), 24-36. 